\title{
The Sociological and Psychological Effect of Media Content on Ghanaian Journalists and Entrepreneurs: An Empirical Analysis
}

\author{
Desmond Onyemechi Okocha ${ }^{1}$ and Dr. Yogesh Kumar Gupta ${ }^{2}$
}

\begin{abstract}
This paper explores the role of the media in shaping the perceptions and attitude of their audience. Media institutions weather traditional or new construct content in the form of messages and interpret them within the context of those messages. Whatever content is portrayed through media should be interpreted correctly by the audience. Modern audience are active participants in the meaning making process. That understanding is formed based on how individual constructs meanings for the symbols, images or events that they see through media and this happens only when their culture gives shared interpretations to those media content.
\end{abstract}

In the global context and most recently in Africa, the backlash against how media portrayals have reached a fever pitch. Studies have shown that in developed countries, youths and the business community are high consumers of media products both for information and entertainment purposes. However, little is known about the Ghanaian situation.

Therefore, this research did seek to empirically investigate the perception of Ghanaian journalists and entrepreneurs on media portrayals and their effect on society. The purpose was to provide scholarly information to put speculations on the subject matter to rest.

Keywords: Media Representation, Ghanaian journalists, entrepreneurs, Perception and Attitude, Media Effect.

\section{Introduction}

Our perception of the world is based on the information we obtain. Perception is the subsequent selection, organization, and interpretation of sensory input--it is the process of obtaining information about both the external and internal environments, which results, via integration utilizing memory, in the conscious experience, recognition, and interpretation of objects, object relationships, and events while an attitude is a psychological construct, it is a mental and emotional entity that inheres in or characterizes a person. They are complex and an acquired state through experiences. It is an individual's predisposed state of mind regarding a value and it is precipitated through a responsive expression toward a person, place, thing, or event (the attitude object) which in turn influences the individual's thought and action. (Perloff, 2016)

The media provide us with news of events happening beyond our immediate surroundings and though situations around the world are

1 Research Scholar, School of Media and Mass Communication, NIMS University, Jaipur 303121, Rajasthan, India.

2 Assistant Professor, School of Media and Mass Communication, NIMS University, Jaipur 303121, Rajasthan, India. touched upon, the topics shown are chosen by editors. Media and public opinion have always been connected, as the media play a significant role in mass communication and reflect issues of the greatest concern to a society. With the increasing role of the media in shaping public opinion, it has become more commercialized on one side and has experienced more limitations and restrictions on the other. Raw information evolves into perceptions based on that information. Thus, any opinion formed based on a news outlet could be considered as having been shaped under the influence of external sources (Astana Times, 2013).

Holiday (2012) noted that media manipulation exploits the difference between perception and reality. The media was long a trusted source of information for the public. Today, all the barriers that made it reliable have broken down. Yet the old perceptions remain. So, manipulators play the volume game. We know that if we can generate enough online buzz people will assume that where there is smoke there is fire... and the unreal becomes real.

Newspapers role is to inform people which comes under surveillance function of media. Newspapers through continuous reporting shape their readers' perceptions via continues reporting which again highlighted the importance of media's construction of social 
reality. And in this specific case media played a very serious role in constructing a reality. Which again supports the notion that media always creates social realities for different groups living in one society. (Sadaf, 2011)

Media could be strong enough through its surveillance function, and it can have a very strong impact through contemporary news media. Media's functions also include socialization function which is to transfer specific culture among people of the society. A journalistic function of media is to provide information on each aspect of all issues of the globe at doorstep of the target audience. Due to this fact media can influence the public opinion and perceptions very easily, because in this era of technological revolution generally public rely on media for immediate and actual information of the surroundings, therefore pubic can easily be influenced from the content of media and it becomes very easy to mold and influence the general public opinion in a dimension and direction where media wants to. In present era media is a tool by which one could control the minds of people or could produce the climate of harmony. But sometimes media can produce conflict between different societal groups and the result would be in the shape of instability within the society or vice versa. This can relate to media construction of social reality, that how media is successful in constructing some important aspects of reality out of nowhere, or sometimes from the facts and happenings that go unnoticed in society. Again, this is very important role of media to construct certain aspects on one issue or more than one issue and then to present in front of public to make certain perceptions accordingly whatever media constructed (Sadaf, 2011).

\section{Research Aims}

The aims of the study are:

1. To investigate how Ghanaian journalists and entrepreneurs perceive the mass media.

2. To find out whether the media play any role in influencing the attitude of Ghanaian journalists and entrepreneurs towards society.

\section{Research Objectives}

And the study, conducted based on two objectives i.e, to find out how journalists and entrepreneurs in Ghana perceive the media representation and to find out if these media representations do have effect on their attitude towards society.

\section{Literature Review}

Tsfati and Cohen (2013) said that the degree of influence and power people attribute to media and their content is another topic of interest for media scholars. One thing that has been clearly establishedis that such attributions are inaccurate. Several key findings point to the conclusion that the way we view the media has as much to do with how we view ourselves (or would like to view ourselves) and others than with an assessment of the media or media content. Davison (1983) identified the original bias that is referred to as the third - person perception

When considering perceptions of media in a volume on media effects, it is important to stress that the effects of perceptions of media are conceptually separate from the direct effects of a specific media text.

Davison (1983) identified the original bias that is referred to as the third - person perception (TPP), namely that people attribute greater power to the media when they are asked about its effect on others than when they are asked about media influence on themselves

Tsfati and Cohen (2013) went further to state that:

According to the cognitive account of the TPP, people's perceptions of media impact are the result of their best guess, using what they know about the world in order to reach as accurate an answer as possible to a question to which even media scholars do not have the real answer. Cognitive explanations attribute errors in estimation not to self - serving biases but to more general cognitive biases.

These include the attribution bias (people acknowledge the impact of external factors such as persuasive intent when they estimate the potentially undesirable impact of media on themselves, but when estimating that same effect on others, they concentrate on the innate characteristics of other people, such as gullibility; Gunther, 1991 ), and self categorization theory (when people estimate media influence, they take into account what they know about the norms of the in - group and those of the out - group; Reid, Byrne, Brundidge, Shoham, \& Marlow, 2007).

According to one of the most studied cognitive explanations, people hold naïve theories of media influence. According to these "magic bullet - like" theories, greater exposure leads to greater media impact, and thus, when people estimate the impact of media content on others, 
they consider what they know about the exposure of these other people to the specific media content (pg.10).

Shewmaker (2013) in her submission said the power of television to influence a person's perception of reality whether it supports his or her own experiences or not speaks to the importance of investigating the content of the messages that are sent through media in general.

It follows that mass media influence how users of media come to think about gender roles, sexuality, attractiveness, desirability and appropriate behavior. We often hear things like, "Media doesn't matter...." But, Gerbner's theory and the recent work by Ward and others tells us that media does matter.

\section{Research Questions and Hypotheses}

Research questions and hypotheses of the study are as follows.

RQ1: How do Ghanaian journalists and entrepreneurs perceive the media?

RQ2: Do Ghanaian journalists and entrepreneurs believe that media representations influence their attitude towards societal issues?

H1: Ghanaian journalists and entrepreneurs perceive media representations as realities.

H2: Ghanaian journalists and entrepreneurs agree that media have effect on their attitudes towards society.

\section{Research Instrument}

Instrument was developed and distributed among the sample whereas sample was selected using convenient sampling from Ghanaian journalists and entrepreneurs. Actual questionnaires received were 300 consisting of 200 journalists and 100 entrepreneurs.

Questionnaire was comprised of closed ended questions to know the journalists and entrepreneurs Perception, which is an important variable of study and it was further broken down for data analysis. A pilot study was conducted with a sample of 15 journalists and 5 entrepreneurs, and with minor changes in the instrument a final questionnaire was developed by having 12 questions in all along with demographic information.

Questions were drawn to elicit information on how many students read newspapers, which newspaper they read and which source of news they prefer most and where the respondents like to read the newspapers, i.e. either at home, library or office., rest of the questions dealt with issues on media perception and effect on attitude.

\section{Data Analysis and Discussion}

\section{Chart 1: Sex Distribution of Respondents}

Chart 1 shows the sex distribution of the respondents. From the Chart it is evident that a total of 100 entrepreneurs participated in the survey. Of this number, $55(55 \%)$ were males while $45(45 \%)$ were females. Meanwhile, 200 journalists participated in the survey of which 124 $(62 \%)$ were males and the remaining $76(38 \%)$ were female journalists. This table shows that the two genders were adequately represented in the research.

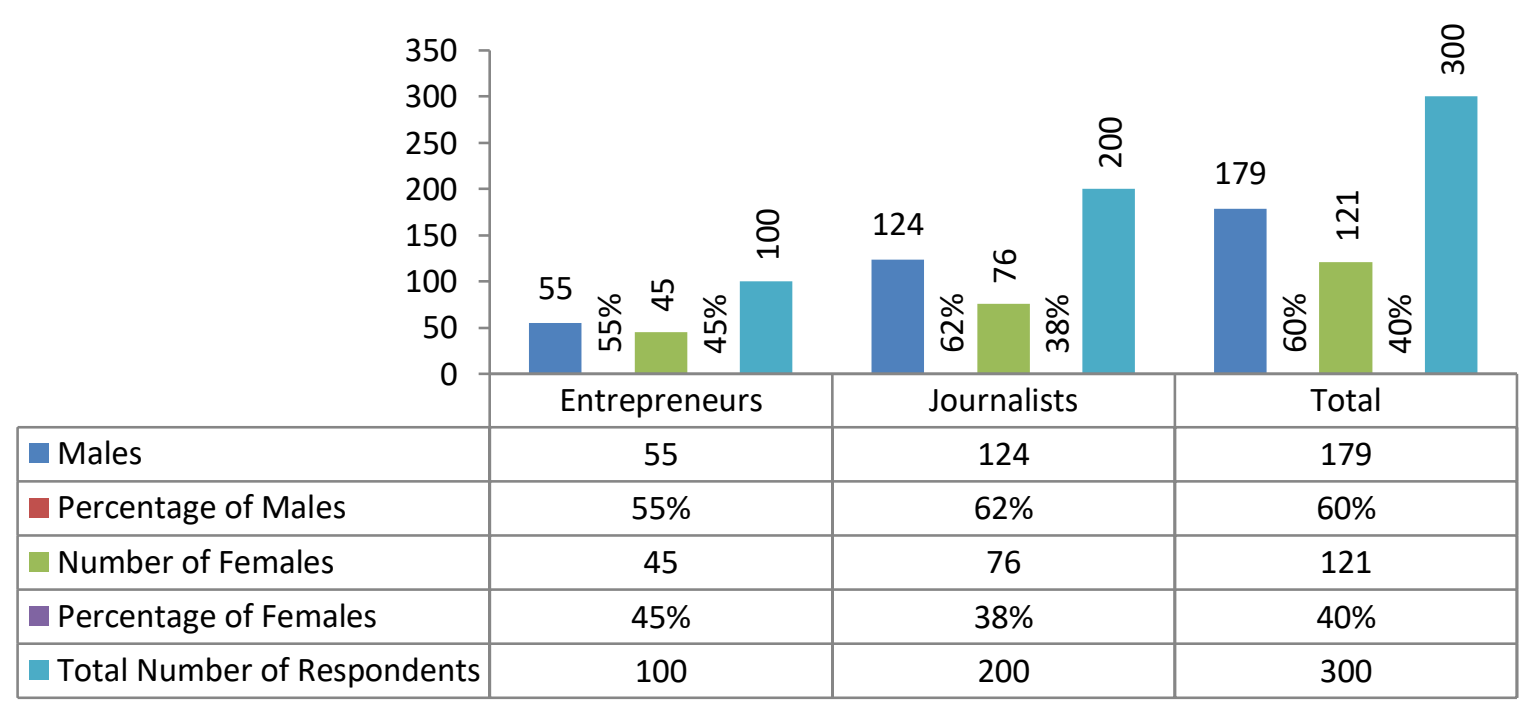

Chart - 1 


\section{Chart 2: Age Distribution of Respondents}

Chart 2 shows the age distribution of the survey respondents. Out of a total of 100 entrepreneurs that took part in the exercise, 7 (7\%) were below these data set, it is obvious that $99 \%$ of the journalists were above 20 years of age. On the whole, about $96 \%$ of the respondents were above 20 years of age.

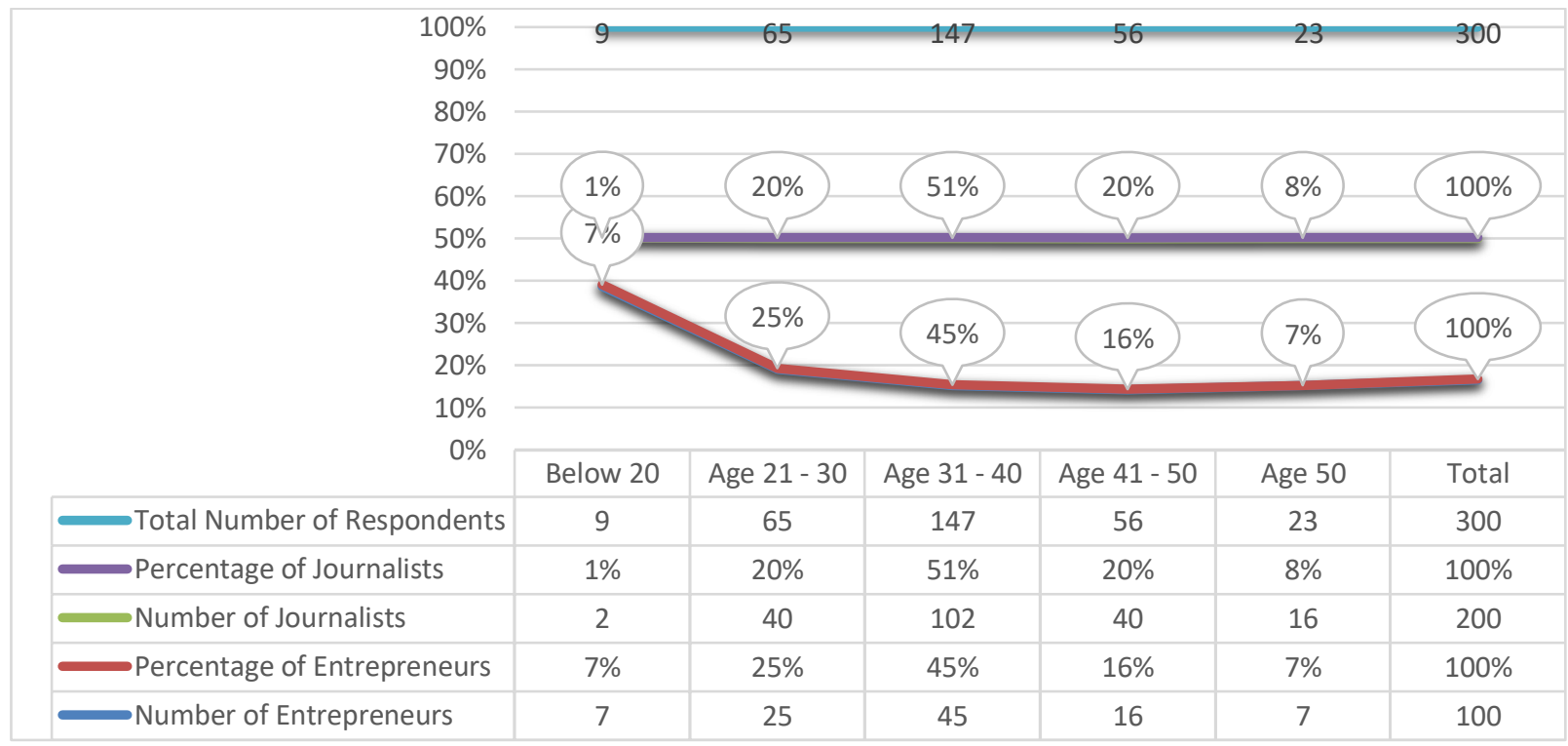

\section{Chart - 2}

20 years of age, $25(25 \%)$ were between $21-30$ years, $45(45 \%)$ were between the range of $31-40$ years, $16(16 \%)$ were between the range of $41-50$ years while 7 (7) were above 50 years of age. These data show that $93 \%$ of the entrepreneurs were above 20 years of age and therefore matured enough to participate in the survey. On the other hand, out of a total of the 200 journalists that took part in the survey, $2(1 \%)$ were below 20 years of age, $40(20 \%)$ were between 21 and 30 years, 102 (51\%) were reportedly between 31 and 40 years, $40(20 \%)$ were between 41 and 50 years while the remaining $16(8 \%)$ were above 50 years. From

\section{Chart 3: Length of stay in Ghana}

Chart 3 shows the length of time the respondents have lived in Ghana. The essence of these data was to ascertain whether the respondents were well positioned to answer questions pertaining to the country. Out of the 100 entrepreneurs, 2 (2\%) had lived for between 1 - 5 years in Ghana, 1 (1\%) for 6 - 10 years, $1(1 \%)$ for 11 - 15 years, $17(17 \%)$ for 16 - 20 years and $76(76 \%)$ for more than 20 years. For the journalists, $8(4 \%)$ had lived in Ghana for 6 - 10 years, 12 (6\%) for 11 - 15 years, $24(12 \%)$ for 16 - 20 years while $156(78 \%)$ had lived in Ghana for more 20 years. This analysis

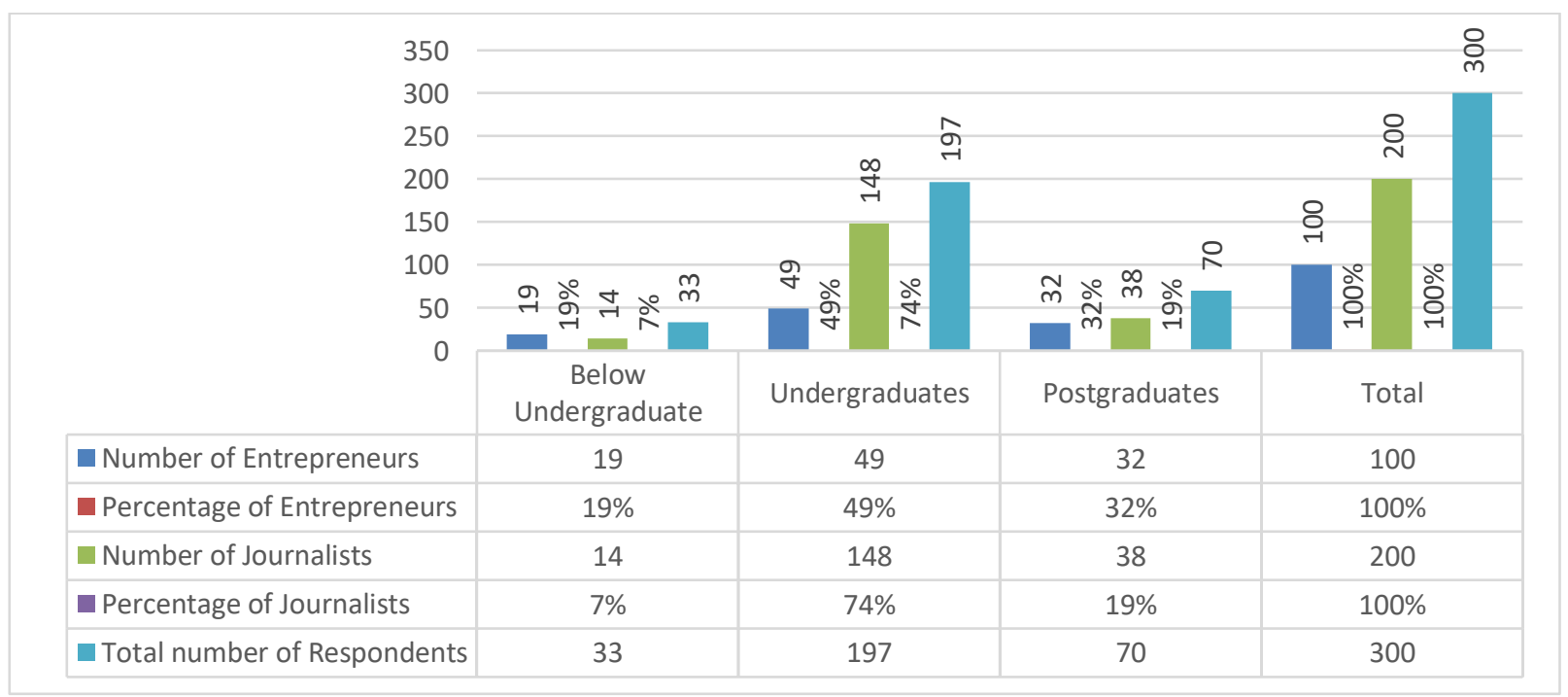


shows that generally about $96 \%$ of the total respondents had lived for 6 years or more in Ghana before the period of this survey. Subsequently, they are sufficiently qualified to participate in the research survey.

\section{Chart 4: Educational Qualification of} Respondents that $7 \%$ of the journalists were not university graduates, $74 \%$ have first degree while the remaining $19 \%$ had postgraduate qualifications. These data show that $89 \%$ of the total respondents were university graduates so they were in a good position to take part in the research survey.

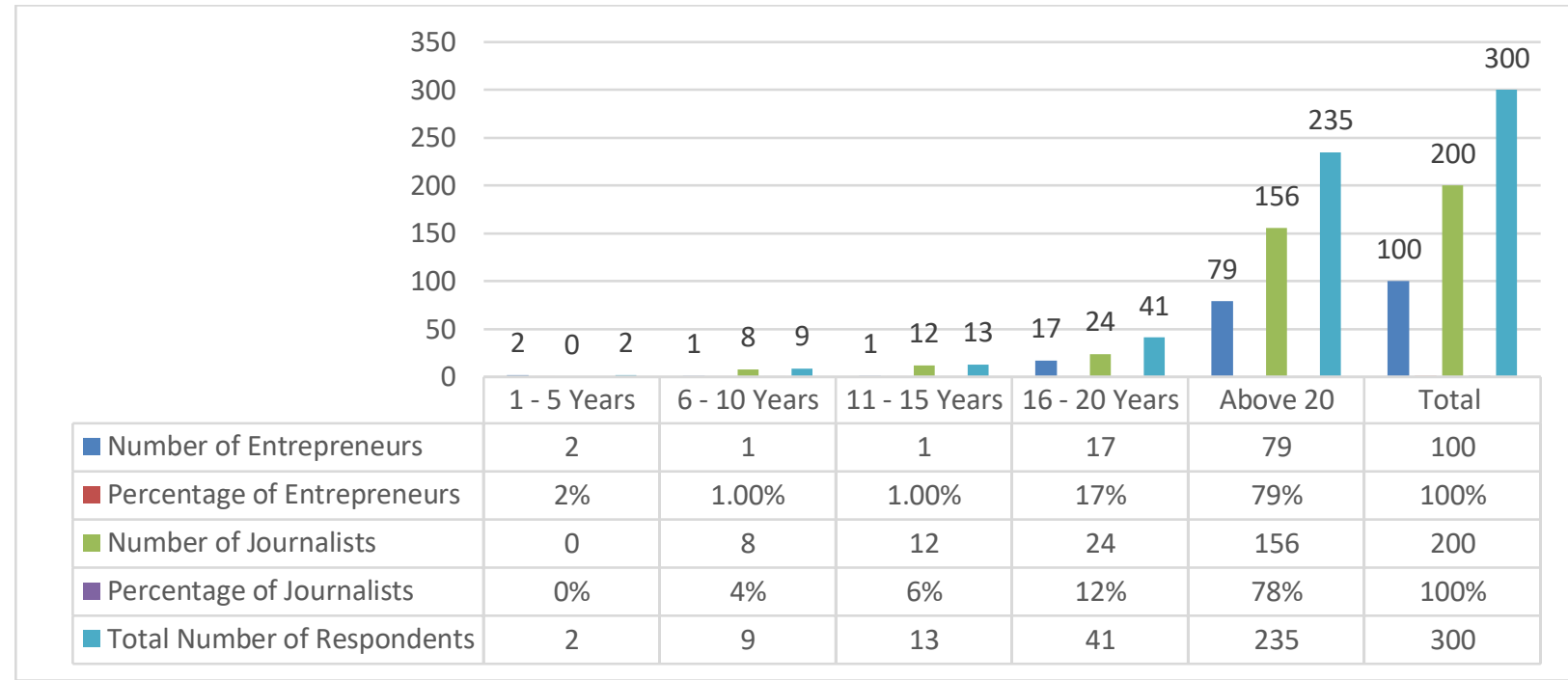

\section{Chart - 4}

Chart 4 shows the educational qualification of the respondents. It was important to know if they were educated enough to be involved in the research process though the basic requirements for involvement in the survey were merely ability to read and write, maturity and being a Ghanaian. The analysis depicted by the above Chart shows that $19 \%$ of the entrepreneurs were below bachelor's degree holders, $49 \%$ had first degree education while the remaining $32 \%$ were postgraduate graduates. The chart also shows

\section{Chart 5: Newspaper Awareness}

Chart 5 shows the awareness of the respondents concerning the four major newspapers in Ghana. Out of a total of the 100 entrepreneurs who participated in the survey, $86 \%$ were familiar with Daily Graphic, 83\% with The Ghanaian Times, $73 \%$ with The Ghanaian Chronicle and 83\% with the Daily Guide. For the respondents who were journalists, $100 \%$ of them were familiar with all the newspapers under review. Judging from these data, it is evident that more than $95 \%$ of the total

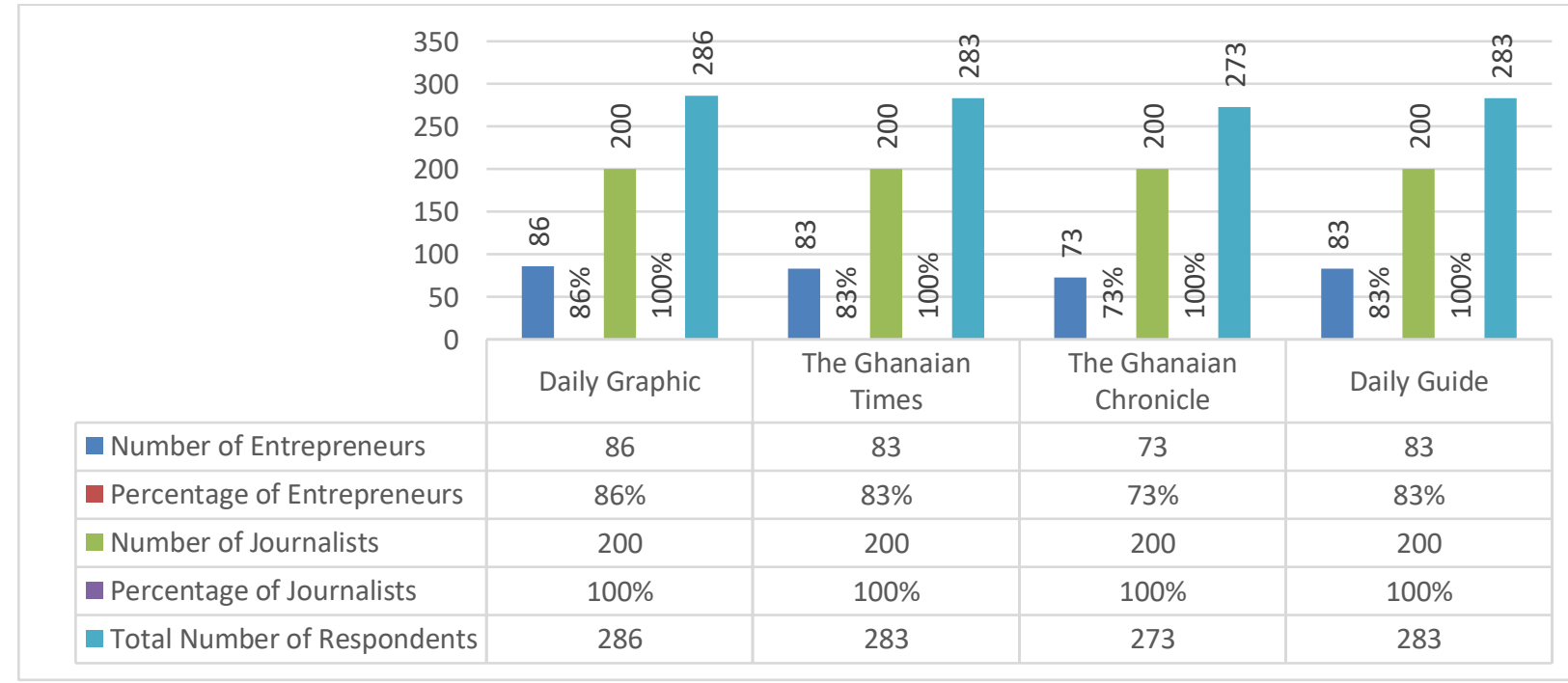

\section{Chart- 5}


respondents were aware of all the listed newspapers used for the investigate. This finding means all the respondents met this criterion for inclusion in the research survey.

Chart 6: How often Respondents Read Newspapers respondents read newspapers on daily basis while $64(21 \%)$ read newspapers weekly. This finding shows that about 284 (94\%) of the total respondents were regular readers of newspapers.

Chart 7: How often respondents read selected Ghanaian dailies

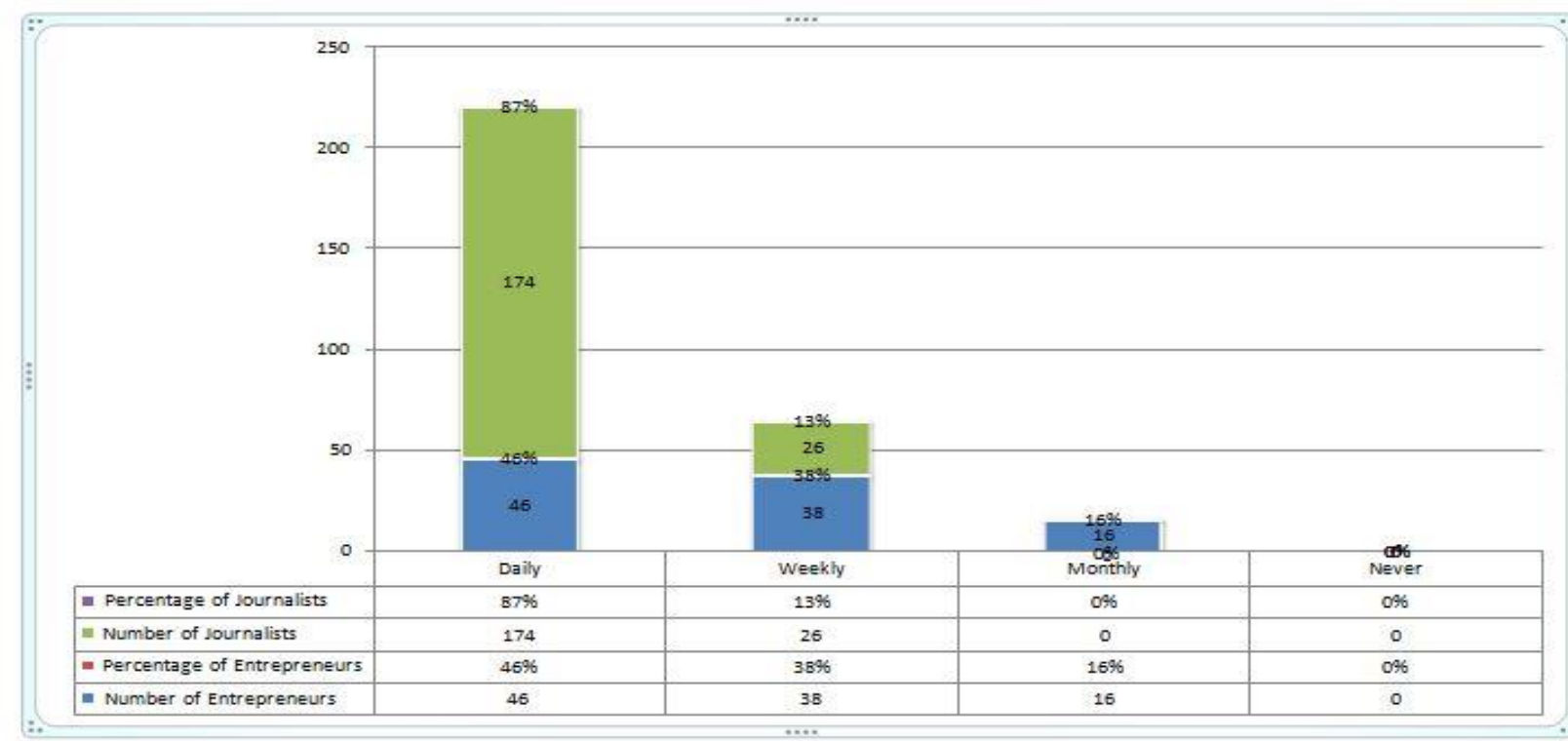

Chart - 6

Chart 6 shows how often respondents read newspaper as it was a vital item in the survey questionnaire. The researcher was interested in respondents who were heavy readers of newspapers. The Chart above shows that among the entrepreneurs, 46 (46\%) read newspapers on a daily basis, 38 (38\%) read newspapers weekly while $16(16 \%)$ read monthly. On the part of the journalists, $174(87 \%)$ read newspapers daily while $26(13 \%)$ read weekly. From these data, it can be seen that at least $220(73 \%)$ of the total
Chart 7 represents the data of how often respondents read the four major newspapers in Ghana. For the entrepreneur respondents, 84 (84\%) read Daily Graphic often, 83 (83\%) read The Ghanaian Times, 70 (70\%) read The Ghanaian Chronicle often and 81 (81\%) read Daily Guide often. Looking at the same Chart it shows that 200 (100\%) of the journalists often read Daily Graphic, 196 (98\%) read The Ghanaian Time, 190 (95\%) read The Ghanaian Chronicle while the same number, 190 (95\%) read Daily Guide. It can be

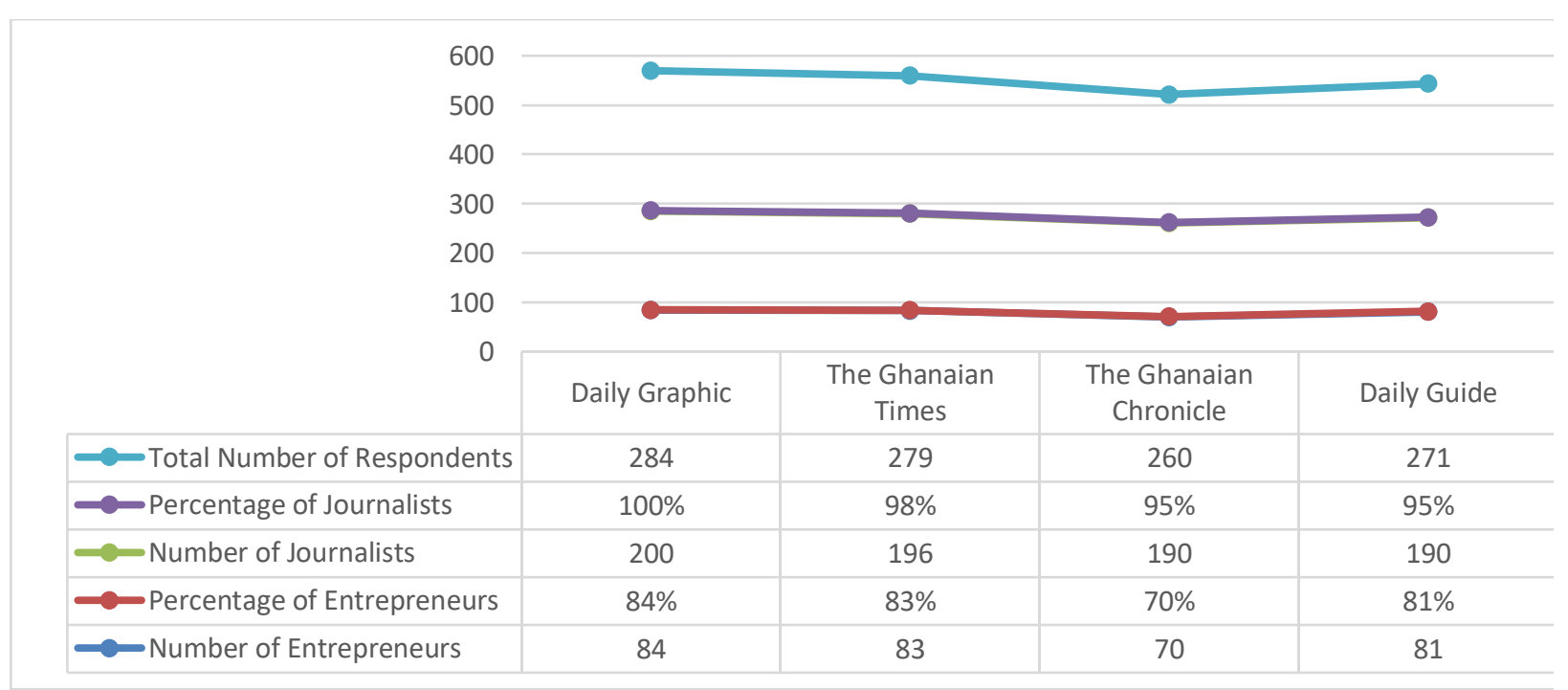

Chart-7 
said that Daily Graphic is most popular with both the entrepreneurs and the journalists. The Chart also shows that more than $90 \%$ of all the journalists often read all the mentioned newspapers. On the average, $284(94 \%)$ of all the respondents often read Daily Graphic.

\section{Chart 8: Sources of Newspaper}

Chart 8 shows respondents source of newspapers. As for the entrepreneurs, 37 (37\%) source their newspapers via traditional (print version) purchase of newspapers, $133(44 \%)$ read online version and 151 (50\%) depended on office copies. Furthermore, from the general outline, it shows that traditional (printed version) newspaper is still popular among respondents as it is evident that 278 (93\%) respondents prefer it.

\section{Chart 9: Media Influence our understanding of reality}

Chart 9 represents the perception of the respondents as to whether media influence their

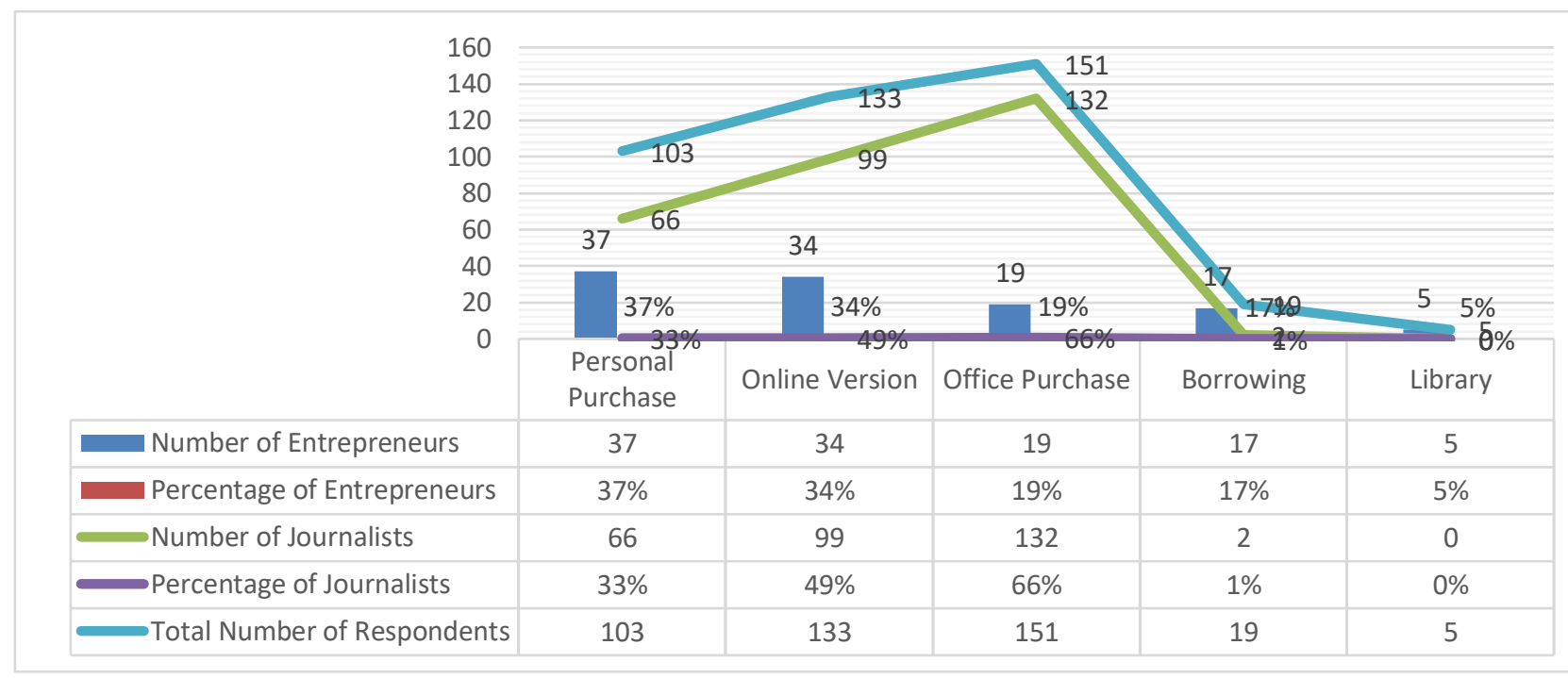

\section{Chart-8}

newspaper purchase, 34 (34\%) source their newspaper online, 19 (19\%) read office copies, 17 $(17 \%)$ borrow from people while $5(5 \%)$ source theirs from libraries. The pattern shown for the journalists is different. Sixty-six $(33 \%)$ of journalists do make personal purchase of newspapers, 99 (49\%) read online version, 132 $(66 \%)$ read office copies and none patronizes the library. Overall, 103 (34\%) makes personal understanding of reality or not. Likert scale was used for this question. Likert scale is a psychometric scale commonly involved in research that employs questionnaires. It is the most widely used approach to scaling responses in survey research, such that the term (or more accurately the Likert-type scale) is often used interchangeably with rating scale, although there are other types of rating scales. When responding

\begin{tabular}{|l|l|l|l|l|l|}
\hline & & & & \\
\hline
\end{tabular}

Chart - 9 
to a Likert item, respondents specify their level of agreement or disagreement on a symmetric agreedisagree scale for a series of statements. Thus, the range captures the intensity of their feelings for a given item. The above Chart shows that out of a total of 100 entrepreneur respondents, 40 (40\%) strongly agree to the proposition that media influence our understanding of reality, 35 (35\%) did agree, 18 (18\%) were neutral; meaning they neither agree or disagree while $7(7 \%)$ disagree. For the journalists, $28(14 \%)$ strongly agree, 138 (69\%) agree, $16(8 \%)$ neutral, $10(5 \%)$ disagree and $8(4 \%)$ strongly disagree. Accumulatively, 68 (23\%) and $173(58 \%)$ of the total respondents did strongly agree and agree respectively that media influence their understanding of reality. This means that 241 (81\%) answered in the affirmative.

Chart 10: Media project a reconstruction of

\section{reality and not the actual reality}

Chart 10 presents the view of the respondents on whether media project a reconstruction of reality and not the actual reality or not. It can be seen from the data shown on the chart that $30(30 \%)$ of entrepreneurs strongly agree, $38(38 \%)$ agree, 25 $(25 \%)$ neutral, $6(6 \%)$ disagree and $1(1 \%)$ strongly disagree while for the journalists, 42 (21\%) strongly agree, 120 (60\%) agree, $26(13 \%)$ neutral, $10(5 \%)$ disagree and $2(1 \%)$ strongly disagree. On aggregate, $72(24 \%)$ of the total number of respondents strongly agree while 158 (53\%) agree. From this analysis, it means $77 \%$ of the total respondents answered in the affirmative that media project a reconstruction of reality (a pseudo-reality) and not the actual reality.

Chart 11: Media influence how we relate with our environment and society

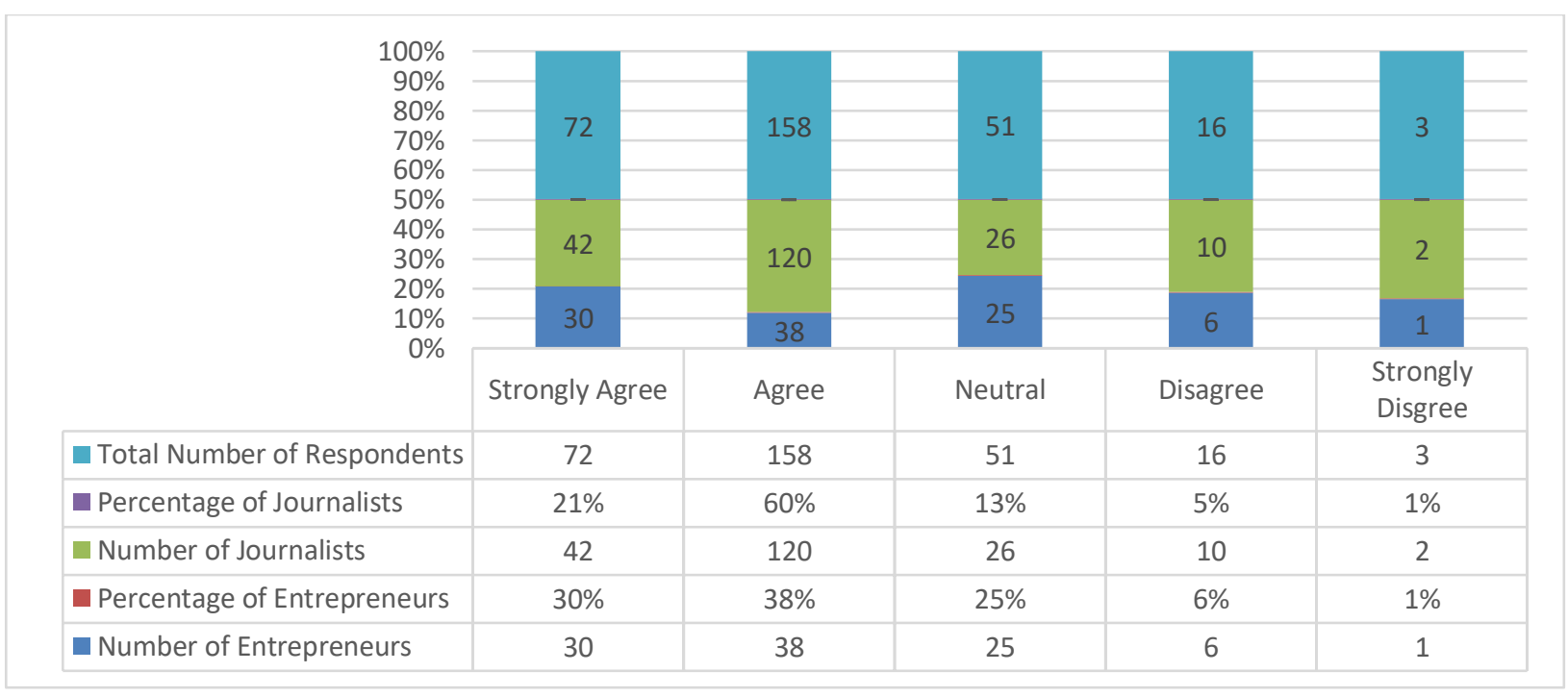

Chart - 10

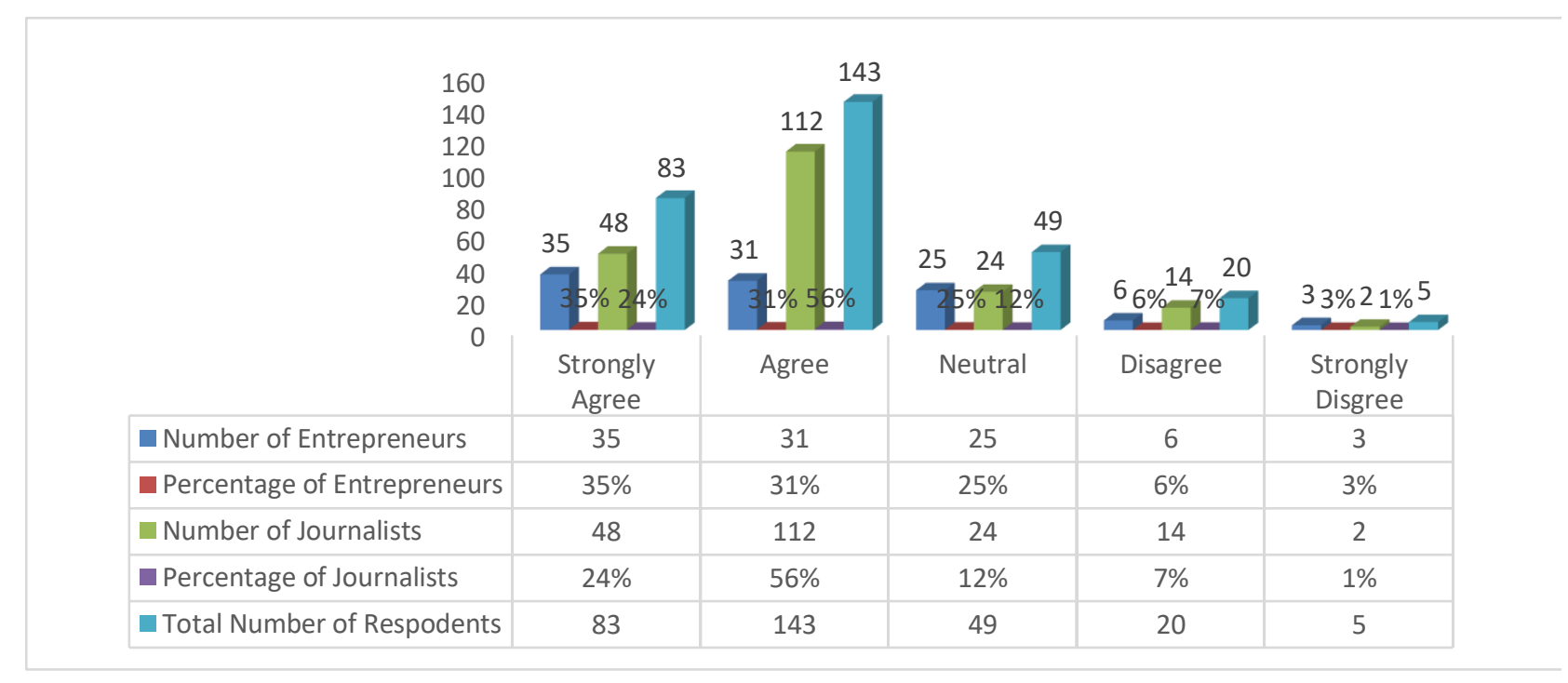

Chart - 11 
Chart 11 shows the views of respondents on the question of whether media influence how we relate with our environment and society. The data analysis shows that for entrepreneurs, 35 (35\%) strongly agree, $31(31 \%)$ agree, $25(25 \%)$ neutral, 6 $(6 \%)$ and $3(3 \%)$ while for journalists, $48(24 \%)$ strongly agree, $112(56 \%)$ agree, $24(12 \%)$ neutral, $14(7 \%)$ disagree and $2(1 \%)$ strongly disagree. Furthermore, $83(28 \%)$ and $143(48 \%)$ of the total number of respondents strongly agree and agree respectively that media influence how they relate with their environment and society. So conclusively, $226(76 \%)$ of the total respondents answered in the positive.

Chart 12: Media is the major source of awareness of happenings outside our environment and country

Chart 12 shows the perception of the respondents on whether media is the major source of their awareness of happenings outside their immediate environment and country. From the above Chart,
II. It shows that $241(81 \%)$ answered in the affirmative that media influence their understanding of reality.

III. Conclusively, 226 (76\%) of the total respondents answered in the positive that media influence how they relate with their environment and society.

IV. On the aggregate, $79(26 \%)$ strongly agree while $131(44 \%)$ agree that media is a key source of knowledge of happenings and events outside their immediate environments and country.

V. More than $95 \%$ of the total respondents were aware of all the list newspapers used for the investigate.

VI. About 284 (94\%) of the total respondents were regular readers of newspapers.

VII. The Daily Graphic is most popular with both the entrepreneurs and the journalists.

VIII. Traditional (printed version) newspaper

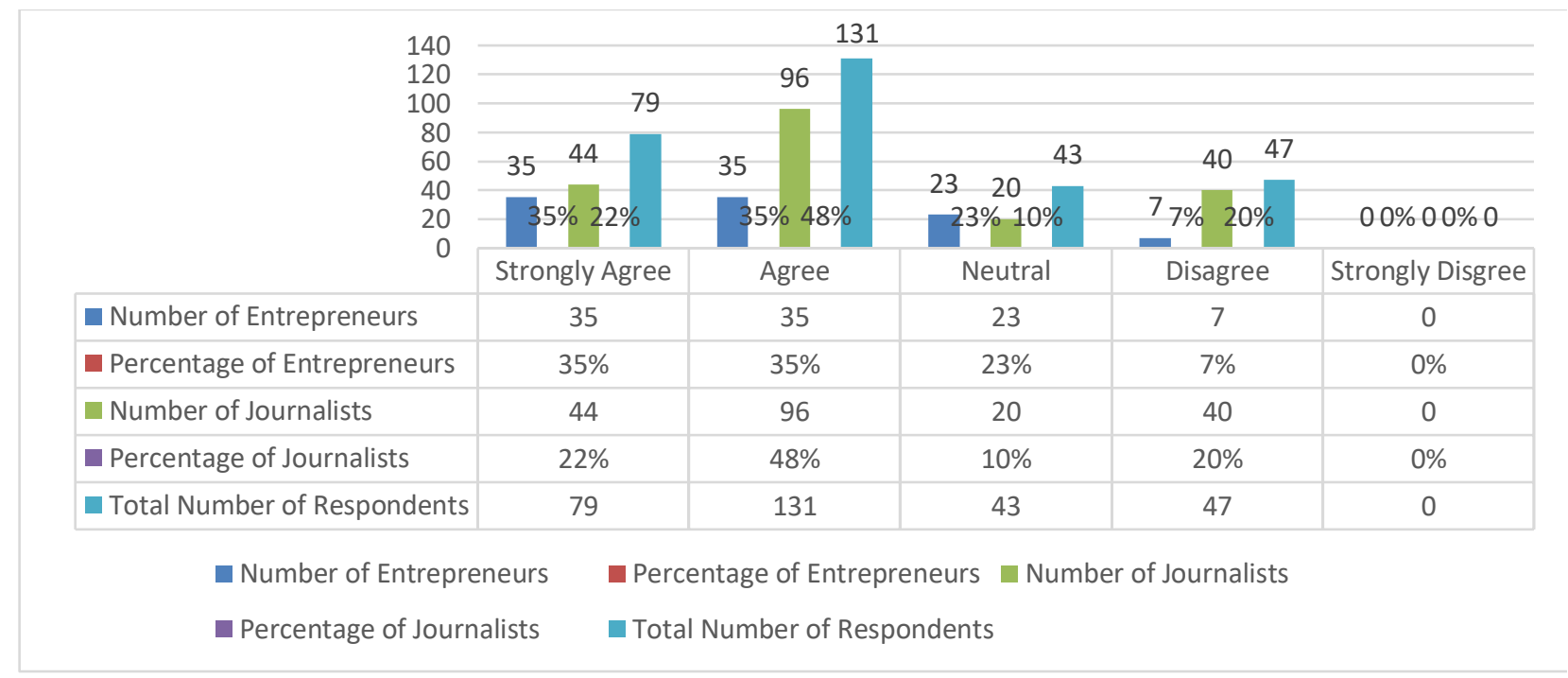

Chart - 12

$35(35 \%)$ of entrepreneurs strongly agree, 35 (35\%) agree, $23(23 \%)$ neutral, $7(7 \%)$ while for on the part of the journalists, 44 (22\%) strongly agree, 96 $(48 \%)$ agree, $20(10 \%)$ neutral, and $40(20 \%)$ disagree. On the aggregate, 79 (26\%) strongly agree while $131(44 \%)$ agree that media is a key source of knowledge of happenings and events outside their immediate environments and country.

\section{Findings}

I. From the analysis $77 \%$ of the total respondents answered in the affirmative that media project a reconstruction of reality (a pseudo-reality) and not the actual reality. is still popular among respondents as it is evident that 278 (93\%) respondents prefer it.

\section{Recommendations}

I. The media has to be more purposeful and objective in the news content it presents to its audience.

2. The consumers of media products need to be more conscious and active in judging the authenticity and objectivity of media contents.

3. Journalists, entrepreneurs and other media products consumers need to leverage on the power of the media in their respective areas of interest. 


\section{Further Research}

For this study, this research design worked effectively. The researcher highly recommends future studies using scientific sampling to extrapolate the results to the population. A scientific approach to this research study would provide rich, concrete data that policy makers can use to support their quests for attitudinal change amongst their target audience and media experts

\section{Conclusions}

Numerous studies, the monitoring of the press and mainstream electronic media, as well as the surveys of public opinion, are some of the tools used to prove the essential influence of the media on public perception and attitudes.

This study on media representation and public attitudes on journalists and entrepreneurs, have shown that the images in the media, the descriptions and the labeling of the media objects, influence public perception and attitudes. So, it is imperative for news editors, journalists and other media players to be conscious of the media portrayals they construct.

\section{References}

Astana Times, (2013). Social Media: Shaping the Way We See the World or Shaping the New World Itself? in EDITORIALS on 20 FEBRUARY 2013.2 Source: http://astanatimes.com/2013/02/socialmedia-shaping-the-way-we-see-the-worldor-shaping-the-new-world-itself/

Davison, W. P. (1983). The Third - Person Effect in Communication. Public Opinion Quarterly, $47,1-15$
Holiday, R. (2012). What is Media Manipulation? --A Definition and Explanation. Source: https://www.forbes.com/sites/ryanholida y/2012/07/16/what-is-mediamanipulation-a-definition-andexplanation/\#5d3c09b63939

Kosho, J. (2016). Media Influence on Public Opinion Attitudes Toward the Migration Crisis. International Journal of Scientific \& Technology Research. Volume 5, Issue 05, May 2016

Sadaf, A. (2011). Public Perception of Media Role. International Journal of Humanities and Social Science Vol. 1 No. 5; May 2011

Shewmaker, J. (2013). Does Media Matter: Media and Perception of Reality. Source: https://jennifershewmaker.com/2013/05/ 22/does-media-matter-media-andperception-of-reality/

Tsfati, Y and Cohen, J. (2013). Perceptions of Media and Media Effects: The Third Person Effect, Trust in Media, and Hostile Media Perceptions. The International Encyclopedia of Media Studies: Media Effects/Media Psychology, First Edition. Edited by Angharad N. Valdivia, Erica Scharrer. Published by Blackwell Publishing Ltd.

Richard M. Perloff, The Dynamics of Persuasion: Communication and Attitudes in the Twenty-First Century, Routledge, 2016. 